\title{
A State of High Anxiety: How Non-Supportive Interviewers can Increase the Suggestibility of Child Witnesses
}

\author{
JEHANNE ALMERIGOGNA ${ }^{1} *$, JAMES OST $^{1}$, RAY BULL $^{2}$ and LUCY AKEHURST ${ }^{1}$ \\ ${ }^{1}$ Department of Psychology, University of Portsmouth, Portsmouth, UK \\ ${ }^{2}$ School of Psychology, University of Leicester, Leicester, UK
}

*Correspondence to: Jehanne Almerigogna, Department of Psychology, University of Portsmouth, King Henry

Building, King Henry I Street, Portsmouth PO1 2DY, England, UK. E-mail: jehanne.almerigogna@port.ac.uk

\section{SUMMARY}

The present study examined the effects of state and trait anxiety on 8-11 years old children's susceptibility to misleading post-event information. Participants' state and trait anxiety were measured, after which they watched an extract from a children's movie. They were then individually interviewed using either a supportive or a non-supportive style. During the interviews, the children were asked 14 questions about the movie, seven of which were control and seven contained misleading information. After the interview, their state anxiety was measured again. Results showed that participants interviewed in a non-supportive style were more likely to provide incorrect answers to misleading questions. Furthermore, participants who scored highly on both trait and post-interview state anxiety measures more often responded incorrectly to misleading questions. Also, pre-to post-interview changes in state anxiety were correlated with more incorrect responses to misleading questions.

Typically, researchers looking at the suggestibility of child witnesses have focused their attention on cognitive factors (Ceci \& Bruck, 1993) and on the effects of certain questioning styles (Fivush, Peterson, \& Schwarzmueller, 2002). However, studies have now started to examine the influence of social and individual factors on the testimony of these witnesses (e.g., Davis \& Bottoms, 2002a; Ridley, Clifford, \& Keogh, 2002). The present study investigated two such factors: interviewer manner (a social factor) and anxiety (an individual factor). To examine these two factors, it focused on three questions. First, can the behaviour of interviewers affect the quality of the information given by the children they are 
interviewing? Second, does the level of anxiety experienced by children affect their accuracy or suggestibility? And finally, is there an interaction between the interviewer manner and the child's level of anxiety?

\section{WHAT FACTORS CAN AFFECT THE QUALITY OF INFORMATION PROVIDED BY CHILD WITNESSES?}

As Ceci and Bruck (1993) noted, cognitive capacities are only one of a number of possible factors that can affect the quality of information children provide in forensic interviews. Other social and situational factors are likely to be equally important. The manner or behaviour of the interviewer is one such factor. During an interview, an interviewer can adopt a generally supportive or non-supportive behaviour. For example, a supportive interviewer might be smiling, making eye contact, sitting with an open body posture and building rapport with the interviewee, whereas a non-supportive interviewer might be cold and distant, avoiding smiles and eye contact. Bull (1998) argued that an interviewer who adopts a negative behavioural manner creates an interpersonal environment in which a child witness may not feel comfortable or at ease. Such non-supportive environments may not really help in obtaining full and accurate reports from child witnesses (Wood, McClure, \& Birch, 1996). One common way of reducing these negative effects would be for the interviewer to behave in a supportive manner (Moston, 1989). Yet, the effect of interviewers' social support on child witnesses is a sensitive subject in eyewitness research because it has generally been thought that supporting children during interviews could actually increase their suggestibility by augmenting their desire to comply with and be agreeable to the interviewer (Moston \& Engelberg, 1992). However, several studies have now demonstrated that quite the opposite may be likely to happen (Bottoms, Quas, \& Davis, in press). For example, Carter, Bottoms, and Levine (1996) found that a supportive interviewer actually reduced the suggestibility of child witnesses. In their study, 5-7 year old children were interviewed in either a supportive manner (i.e., the interviewer was friendly, smiled and gazed often at participants, sat in a relaxed manner and attempted to build rapport) or in an intimidating manner (i.e., the interviewer was cold and distant, did not smile or gaze much and did not attempt to build rapport with the children). Their results showed that whilst interviewer manner had no effect on the children's free recall, it did have an effect on their level of suggestibility. Those children who were interviewed in the supportive manner demonstrated an increased resistance to misleading questions compared to those interviewed in the intimidating manner. Carter et 
al. (1996) hypothesised that the positive effect on suggestibility of an interviewer who behaved in a supportive manner could be due to this style of interviewing making children less anxious. Davis and Bottoms (2002a) conducted an experiment to test this assumption directly. They showed that social support in the form of positive reinforcement and behaviours displayed by the interviewer during an interview might, as previously demonstrated, increase children's resistance to misleading suggestions. Positive reinforcements were defined by the interviewer building rapport, smiling and gazing often, speaking with a warm tone of voice and sitting closely and in a relaxed manner. Their results also indicated that the interviewer-provided social support served to reduce children's level of anxiety. That is, children interviewed by the supportive interviewer felt less anxious during the interview than children interviewed by the intimidating interviewer. Although Davis and Bottoms did not find any effect of anxiety on children's suggestibility, they suggested that anxiety might be a mediating factor between interviewers' behaviours and suggestibility.

\section{WHAT ARE THE EFFECTS OF ANXIETY ON THE ACCURACY AND SUGGESTIBILITY OF CHILD WITNESSES?}

Goodman, Rudy, Bottoms, and Aman (1990) observed that child witnesses often give only short accounts of the events they have witnessed. Part of the reason why this happens, they noted, might be the anxiety-inducing nature of interviews. That is, interviews may be experienced by children as anxiety-inducing situations (Moston \& Engelberg, 1992). In the present study, we were therefore interested in the effect of both trait and state anxiety at the retrieval phase, that is, during the interview. Trait anxiety is a stable and enduring personality dimension, which is said to remain constant across different situations. State anxiety, on the other hand, is the anxiety a person experiences in a certain situation (Spielberger, 1972). It is therefore directly linked to the specific characteristics of a situation (Rachman, 2004). In the present study, it was predicted that the two distinct interviewing styles should differently affect children's state anxiety.

Research has shown that the performance of anxious people is usually inferior to that of nonanxious individuals on a variety of cognitive tasks (Eysenck, 1992). Eysenck (1997) proposed that at event-recall, high trait anxious individuals are more likely to be concerned about failure and self-presentation than low trait anxious ones. This could increase their suggestibility by using cognitive resources which would otherwise be applied to retrieval strategies and memory monitoring (Williams, Watts, MacLeod, \& Mathews, 1988). For state 
anxiety, Farber and Spence (1953) argued that high levels of state anxiety at retrieval reduce performance on complex tasks while having facilitating effects on more simple exercises. High-state anxious persons are more likely to misinterpret a question or to feel unable to access an answer they are confident they know (Sarason, 1980). Accordingly, highly anxious individuals should perform more poorly in suggestibility studies than low anxious participants (Wolfradt \& Meyer, 1998). Gudjonsson (1988) found support for this hypothesis in a study with adults in which he demonstrated that high levels of both state and trait anxiety, as measured by the Spielberger State-Trait Anxiety Inventory (Spielberger, Gorsuch, \& Lushene, 1970), were related to high scores on his scale of interrogative suggestibility (the Gudjonsson Suggestibility Scale: Gudjonsson, 1984). However, Ridley and Clifford (2004) found that adult participants scoring higher on a state anxiety measure were actually less likely to answer incorrectly to misleading questions. Yet, by only measuring state anxiety, Ridley and Clifford may have missed the possible interaction of pre-existing trait anxiety with state anxiety. They also might have overlooked the possibility that anxiety acts as a mediator between suggestibility and other factors (e.g., interviewer manner).

\section{HOW COULD THE INTERACTION BETWEEN THE INTERVIEWERS' BEHAVIOUR AND CHILD WITNESSES' ANXIETY AFFECT THEIR SUGGESTIBILITY?}

The present study attempted to extend Carter et al.'s (1996) study by manipulating interviewer manner and measuring both state and trait anxiety. The present study's aim was to examine the interacting effects of interviewing manner and anxiety on the suggestibility and memory accuracy of child witnesses. Participants first watched a short film after which their trait and state anxiety were measured. They were then individually interviewed in either a supportive or a non-supportive manner and asked seven control and seven misleading questions. After the interview, each child completed a second state anxiety questionnaire. In line with previous research (e.g., Carter et al., 1996; Davis \& Bottoms, 2002a), it was predicted that a non-supportive interviewer would lead children to answer more of the misleading questions incorrectly. Furthermore, it was predicted that children with higher state and trait anxiety scores would exhibit a higher tendency to answer misleading questions incorrectly compared to children with lower anxiety scores. Finally, it was predicted that the state anxiety of participants would differ depending on which interviewing style they experienced. Children interviewed in a supportive manner should show a decrease in state 
anxiety whereas those interviewed in a non-supportive manner should demonstrate an increase in state anxiety. Furthermore, whether these changes in levels of pre- to postinterview state anxiety were related to participants' suggestibility scores was also examined.

\section{METHOD}

\section{Participants}

Seventy-four children participated in the experiment. Following cleaning and screening, data from five children were removed due to large numbers of missing values which, because of the nature of analysis, could not be replaced with a measure of central tendency such as a median or a mean. Of the remaining 69 children, there were 35 girls and 34 boys. The mean age for this sample was 9.27 years (range $=$ between 8 years and 11.5 years, $\mathrm{SD}=0.72$ years). The participants were all pupils from a primary school. Four classes took part in the experiment, 2 year three classes (ages 8-10 years) and 2 year four classes (ages 9-11 years). One class from each year was assigned to either the supportive or the non-supportive interview style conditions. Children's age did not differ as a function of whether they were interviewed by a supportive or non-supportive interviewer $(\mathrm{p}>0.05)$.

\section{Materials}

\section{Anxiety questionnaire}

The questionnaire used to measure trait and state anxiety was Spielberger, Edwards, Lushene, Montuori, and Platzek's (1973) State-Trait Anxiety Inventory for Children (STAI-C). It comprised 40 questions printed on two sheets. The first part of the questionnaire consisted of 20 questions designed to measure children's trait anxiety. It included statements such as 'I am shy', 'I notice my heart beats fast' and 'I worry about what others think of me'. These questions were answered by indicating 'hardly-ever', 'sometimes' or 'often'. The other 20 questions measured their state anxiety with statements like 'I feel very calm, calm or not calm', 'I feel very nervous, nervous or not nervous' and 'I feel very terrified, terrified or not terrified'. The instructions were written on top of the questionnaire. The same questionnaire was distributed to all participants.

\section{Movie}


The clip shown to the participants was an extract from the U-rated movie 'Madeline'. It was 5 minutes and 17 seconds long. All pupils saw the same clip. An outline of the event is appended.

\section{Interviewer manner manipulation}

In line with previous research (e.g., Carter et al., 1996; Davis \& Bottoms, 2002a), the two interviewing styles (supportive and non-supportive) were distinguished by the interviewer's use of different verbal and non-verbal behaviours. In the non-supportive interviews, the interviewer adopted a formal and stern attitude. She was sitting with her legs crossed and arms folded, leaning back in her chair. Her behaviour was serious and she did not smile. She made very little attempt to build rapport with her interviewees. She was wearing black formal clothes and spectacles. For the supportive interviews, the same interviewer appeared a lot more relaxed. She adopted an open body posture. She tried to build rapport with the children, looked at them more and acted in a friendlier manner. She was wearing coloured casual clothes and did not wear spectacles.

\section{Structure of the interview and interview questions}

For the purpose of the study, 14 questions were designed based on the movie clip. In order to control for item-specific confounds in the ease with which participants might be misled about certain aspects of the movie, each question was designed to have both a control and a misleading form. For example, a question asking children what was on the kitchen table would in its control form be 'Was there anything on the table'? and in its misleading form 'Were there eggs on the table'? Children were presented with either the control form of a question or the misleading form of it. No child was presented with the same question in different forms (i.e., control and misleading). Each question was presented in its control and misleading version the same number of times.

Each child was asked 14 questions, seven control and seven misleading. The questions were presented to the children orally by the interviewer. Questions were asked once and followed the sequence of the movie. The answers to the seven control questions were used to measure children's memory accuracy (thus giving a 'memory accuracy' score of 0-7). Their responses to the seven misleading questions measured their level of susceptibility to misinformation (thus giving a 'suggestibility' score of 0-7).

\section{Procedure}


For the first part of the experiment, the children were tested in groups. First, the STAI-C was distributed to them. The instructions, which were written at the top of the sheets, were read aloud by the investigator. They were also told that they were free to ask questions at any time if there was something they did not comprehend in the questionnaire. There was no time limit for the completion of the STAI-C although none of the participants took more than 15 minutes to finish it. The children then watched the movie in groups of 14 to 23 after which they were individually interviewed. After each interview, participants were presented with a second state anxiety questionnaire which comprised the same 20 questions which formed the state anxiety part of the STAI-C. The children were then thanked and returned to their usual class activities. Interviews lasted between 7 and 15 minutes. Once all pupils had participated, the experimenter debriefed them in groups as to the aims of the study and answered any questions they had.

\section{RESULTS}

\section{Effects of interviewing style on memory accuracy and suggestibility scores}

A MANOVA was performed with interviewing style (supportive or non-supportive) as the independent variable, and the memory accuracy and suggestibility measures as dependent variables. To verify whether the results could have been influenced by either the age or the gender of participants, these two variables were entered as covariates. There was an effect of interviewer manner for suggestibility scores (i.e., incorrect responses to misleading questions) $\left(F_{1,65}=27.21, p<0.001\right.$, partial $\left.\eta^{2}=0.29\right)$. The mean scores indicated that participants interviewed in a non-supportive manner gave significantly more incorrect responses to misleading questions $(\mathrm{M}=2.03, \mathrm{SD}=1.05)$ than those being interviewed in a supportive manner $(\mathrm{M}=0.86, \mathrm{SD}=1.06)$. There was no effect of interviewing style on accuracy scores ( $p>0.05)$ and there was no effect of age or gender on either the accuracy or suggestibility scores (both $\mathrm{p}>0.05$ ).

\section{Effects of state and trait anxiety on memory accuracy and suggestibility scores}

In order to investigate the effect of state and trait anxiety on children's memory accuracy and suggestibility, median-splits were performed on participants' trait anxiety scores and postinterview state anxiety scores. For trait anxiety, the median score was 36 and for post-state anxiety the median score was 29. Participants with scores under the median were categorised as low-state or low-trait anxious whereas scores above the median were categorised as high- 
state or high-trait anxious. This resulted in a combined anxiety variable with four levels (i.e., high-trait/high-state, high-trait/low-state, low-trait/high-state, low-trait/low-state). Table 1 shows the means and standard deviations of the memory accuracy and suggestibility scores for each of these groups.

Table 1. Means and standard deviations for the number of correct answers on control questions and the number of incorrect answers on misleading questions for the four levels of anxiety groups.

\section{Correct control}

Incorrect misleading

\begin{tabular}{ccccc}
\hline & Mean & $S D$ & Mean & $S D$ \\
\hline High-trait/high-state $(\underline{\mathrm{N}}=21)$ & 4.33 & 1.28 & 1.95 & 1.16 \\
\hline High-trait/low-state $(\underline{\mathrm{N}}=14)$ & 4.86 & 1.17 & 1.5 & 1.02 \\
\hline Low-trait/high-state $(\underline{\mathrm{N}}=11)$ & 3.91 & 1.45 & 1.36 & .81 \\
\hline Low-trait/low-state $(\underline{\mathrm{N}}=23)$ & 4.35 & 1.3 & .91 & .9
\end{tabular}

A MANOVA was performed with the four levels of anxiety as the independent variable, and accuracy and suggestibility scores as the dependent variables. There was a main effect of anxiety on the suggestibility scores $\left(F_{3,65}=4.19, p<0.01\right.$, partial $\left.\eta^{2}=0.02\right)$. Post hoc Tukey tests revealed that only the difference between the low-trait/low-state and the high-trait/highstate anxiety groups for the suggestibility scores was significant $(\mathrm{p}<0.005)$. The means revealed that participants with high scores on both the state and trait anxiety measures gave more incorrect responses to misleading questions $(\mathrm{M}=1.95)$ than children with low state and trait anxiety scores $(M=0.91)$. It should be noted that the same combination of high-trait and high post-interview state anxiety did not have a significant effect on the number of correct responses to control questions.

\section{Relationship between interviewing styles and anxiety}

In order to observe the possible effects of the supportive and non-supportive styles of interviewing on the level of state anxiety of participants, the difference between pre- and poststate anxiety for the two interviewing style groups was examined with an independent t-test. A significant difference between the two groups in terms of pre-interview state anxiety was observed ( $\mathrm{t}_{67}=4.04, \mathrm{~d}=1.00, \mathrm{p}<0.001$; supportive $\mathrm{M}=33.22$, non-supportive $\mathrm{M}=27.88$ ). As the groups were similar in terms of age and gender, the reason for this pre-interview state anxiety difference is unclear. T-tests were also performed to compare the means of the preand post-interview state anxiety scores, which found that the changes between the pre- 
interview state anxiety and post-interview state anxiety were significant for both the supportive group $\left(\mathrm{t}_{35}=5.66, \mathrm{~d}=0.98, \mathrm{p}<0.001\right.$; pre-interview state anxiety $\mathrm{M}=33.22$, postinterview state anxiety $M=28)$ and the non-supportive group $\left(t_{32}=3.84, d=0.74, p=0.001\right.$; pre-interview state anxiety $M=27.88$, post-interview state anxiety $M=31.88$ ). These results suggest that the two different interviewing styles did have an effect on the state anxiety of participants, with the supportive manner decreasing it and the non-supportive one increasing it. No significant difference in terms of trait anxiety scores was observed between the supportive group $(M=36.72)$ and the non-supportive one $(M=36.48)$.

\section{Relationship between state anxiety variations and memory and suggestibility}

To further investigate the possible relationship between anxiety and suggestibility, a new variable was calculated from participants' pre- and post-interview state anxiety measures. The post-interview state anxiety scores were subtracted from the pre-interview state anxiety scores so as to give a pre- to post-interview change in the state anxiety scores of each participant. A positive score on this variable therefore showed that the participant became less anxious during the interview (e.g., a pre-state anxiety score of 30 minus a post-state anxiety score of 25 equals a difference of +5 ) whereas a negative score indicated a rise in state anxiety (e.g., a pre-state anxiety score of 30 minus a post-state anxiety score of 35 equals a difference of -5). Correlations between this new 'change' variable and the performance on control and misleading questions demonstrated that there was no relationship between the state anxiety 'change' variable and number of correct answers to control questions $(r=0.16, p$ $=0.18$ ) but there was a significant negative relationship between the 'change' scores and the number of incorrect answers to misleading questions ( $\mathrm{r}=-0.46, \mathrm{p}<0.001)$. That is, participants who reported feeling less anxious after the interview than before gave less incorrect answers to the misleading questions and those who were more anxious after the interview than before it provided a greater number of incorrect responses to misleading questions (only two of those children feeling more anxious post- than pre-interview had been interviewed by the supportive interviewer. However, their pre- to post-state anxiety differences were very low ( -2 and -3 , respectively) and both children made no incorrect answers to the misleading questions).

\section{Trait anxiety, memory and suggestibility}

The correlation between trait anxiety and the number of correct responses to control questions was significant $(r=0.26, p<0.05)$. That is, children with higher trait anxiety scores were 
more likely to give correct answers to control questions than children with lower trait anxiety levels. The correlation between trait anxiety and the number of incorrect responses to misleading questions was also significant $(\mathrm{r}=0.34, \mathrm{p}<0.005)$. Children with higher trait anxiety scores were more likely to answer misleading questions incorrectly than children with lower trait anxiety scores.

\section{DISCUSSION}

The aim of the present study was to examine the possible effects of interviewing style and levels of state and trait anxiety on children's eyewitness testimony. The results showed that the two different interviewing styles (supportive and non-supportive) had a significant effect on children's suggestibility, with children in the non-supportive group answering significantly more of the misleading questions incorrectly than children in the supportive condition. Furthermore, participants scoring highly on measures of both state and trait anxiety were more prone to give incorrect responses to misleading questions than participants having low scores on these measures. Moreover, the two different interviewing methods appeared to create environments that were, as measured by their post-interview state anxiety scores, experienced differently by children.

\section{Interviewing styles and suggestibility}

The present study demonstrated that an interviewer adopting a non-supportive demeanour could increase children's suggestibility. This is in accordance with Gudjonsson's (1992) argument that interviewer authority would lead children to comply more with whatever an interviewer says thus augmenting their suggestibility. In a similar vein, Goodman, Bottoms, Schwartz-Kenney, and Rudy (1991) noted that an interviewer providing social support, such as smiles and verbal encouragements, to child interviewees significantly lessened incorrect free recall and subsequent errors in response to misleading questions. Engelberg and Christianson (2002) contended that interviewees have to be provided with an environment of safety and support in order to make them feel more comfortable and secure, and to this we can add 'less anxious'. In this way, adult and child interviewees alike may be more able to talk about their memories in a more articulate and complete manner. However, too much support may also decrease performance as interviewers may become too persistent and coercive (Garven, Wood, Malpass, \& Shaw, 1998) and, as Bain, Baxter, and Fellowes (2004) have highlighted, a balance between support and focus on the matter under discussion may be 
needed. Therefore, for improved forensic practice, variables which could possibly influence interviewees and their account of the witnessed event need to be better identified and understood. As demonstrated by the present study, the behaviour of the interviewer plays a key role (Carter et al., 1996). However, more research is needed to further investigate these issues. For example, are there specific aspects of an interviewer's non-verbal or verbal behaviour that have more, or less, of an effect on the accuracy of what child witnesses recall and report?

\section{Anxiety and suggestibility}

Clark and Wells (1995) argued that an anxious person's performance can be diminished by anxiety because of processes such as intrusive thoughts and worry. They stated that anxious people are so preoccupied with their internal sensations and their meanings that they become relatively inattentive to whatever is going on around them. These anxious individuals, their mind full of interfering negative thoughts about themselves and their capacities, with both their self-confidence and their efficacy undermined, would be expected to perform poorly on a cognitively demanding task such as answering questions (Wells, 2005). The findings of the present study are also in line with the processing efficiency theory (Eysenck \& Calvo, 1992), suggesting that highly anxious children might have had fewer cognitive resources available to allocate to the more difficult aspects of the task at hand (i.e., dealing with misleading questions).

The present study found that anxiety was related to suggestibility, but not to accuracy scores. This too, may be best explained in terms of differences in levels of cognitive resources required to answer misleading and non-misleading questions. According to the discrepancy detection principle (Tousignant, Hall, \& Loftus, 1986), memories are less likely to be transformed when one directly detects discrepancies between the original memory and the misinformation (Schooler \& Loftus, 1986). Undetected discrepancies may lead to source misattributions errors, that is, recalling items that were only suggested (Zaragoza \& Lane, 1994). Retrieving answers to non-misleading questions should therefore be, cognitively speaking, a less demanding task than undertaking a memory search to compare misleading information provided by an interviewer with what was initially witnessed. The difference in difficulty and hence cognitive resources required, may explain the finding that anxiety was only related to participants' suggestibility scores and not their memory accuracy scores.

\section{Interviewing styles and anxiety}


The present study found an effect of interviewing style on state anxiety with supportive interviewer behaviours decreasing children's level of state anxiety and non-supportive manners increasing it. Because state anxiety is sensitive to changes in the immediate context (Spielberger, 1972), it was influenced by interviewer behaviours. The more pleasant environment created in the supportive condition may have put children more at ease and, as a consequence, made them feel less nervous. On the contrary, in the non-supportive interviews, participants, feeling more vulnerable and oppressed, became more anxious. This is in line with Carter et al.'s (1996) hypothesis which stated that children should be less anxious when an interviewer behaves in a supportive, as opposed to a non-supportive, manner. This finding is important for applied procedures. It is recognised that forensic interviews are unpleasant experiences for children. Simply by adopting certain behaviours, the interviewer can affect the interviewees' feelings of the situation (Davis \& Bottoms, 2002b). That is, by being more supportive, the interviewer can make children feel more comfortable and less anxious. In this more positive environment, they are likely to report more information of better quality (Goodman et al., 1990) and, as the present study demonstrated, to be better able to resist misleading information.

\section{Limitations of the present study}

The present study measured anxiety with the STAI-C and, although this test has good validity and reliability (Spielberger et al., 1970), its construct has been questioned. Kelly (2004) argued that the trait scale of the STAI comprised a 'worry' component which should actually be considered separately from trait anxiety (Davey, Hampton, Farrell, \& Davidson, 1992). To overcome such problems, previous studies have sometimes measured arousal using participants' physiological responses like heart rate, blood pressure or palm sweating. For example, Quas and Lench (2006) measured children's heart rate while encoding and retrieving information from a fear eliciting video clip. Children with higher heart rate at encoding answered fewer questions incorrectly while those with higher heart rate at retrieval answered more questions incorrectly but only when interviewed by a non-supportive interviewer. Such measures may be more appropriate and accurate to investigate the relationship between witnesses' arousal and suggestibility. The to-be-remembered event used in the present study was a movie clip. As has been argued, movie clips, although rich in information and easily controllable, are not very ecologically valid (Saywitz, Goodman, Nicholas, \& Moan, 1991). They are also rather impersonal and insignificant for the participating children. With such events, children are passive observers and they may 
therefore feel little concern to put all of their attention in the task (Thierry\&Spence, 2004). Several studies (e.g., Krackow \& Lynn, 2003; Nathanson \& Saywitz, 2003) have demonstrated that it is quite possible to involve children in a meaningful activity while remaining ethical. For example, Gilstrap and Papierno (2004) staged an event with a magician visiting the children at school. The children watched and participated in magic tricks, sang and danced. In Krackow and Lynn's study, children were involved in a game of Twister. Such events are both salient and exciting for children. For a better application of laboratory studies and to better mimic the actions of children's memory about a real-life event, it would be better not to use movie clips as the to-be-remembered event.

\section{CONCLUSION}

Situational factors influencing people's memory and suggestibility in forensic interviews have seldom been studied. However, the present study demonstrated that such factors can have a great influence on child interviewees. It was shown that both the behaviour the interviewer adopts while trying to gather information and children's level of anxiety during an interview do affect the quality of the children's answers. Factors such as interviewing manner can be controlled and manipulated in interviews more easily than can individual or cognitive factors (Roberts, Lamb, \& Sternberg, 2004). Future research should therefore focus on these dynamic situational aspects of interviews in order to develop more appropriate procedures for interviewing child witnesses.

\section{ACKNOWLEDGEMENTS}

The authors would like to thank Dr. Michael Fluck, Prof. Graham Davies and two anonymous reviewers for their constructive comments which improved the quality of this paper. The authors would also like to thank the headmaster, teachers, parents and children who participated in this study.

\section{REFERENCES}

Bain, S.A., Baxter, J.S., \& Fellowes, V. (2004). Interacting influences on interrogative suggestibility. Legal and Criminological Psychology, 9, 239-252. 
Bottoms, B.L., Quas, J.A., \& Davis, S.L. (in press). The influence of interviewer-provided social support on children's suggestibility, memory, and disclosures. In M.E. Pipe, M. Lamb, Y. Orbach, \& A.C. Cedarborg (Eds.), Child sexual abuse: Disclosure, delay and denial. Mahwah, NJ: Erlbaum.

Bull, R. (1998). Obtaining information from child witnesses. In A. Memon, A. Vrij, \& R. Bull (Eds.), Psychology and law: Truthfulness, accuracy, and credibility (pp. 188-209). Maidenhead: McGraw-Hill.

Carter, C.A., Bottoms, B.L., \& Levine, M. (1996). Linguistic and socioemotional influences on the accuracy of children's reports. Law and Human Behavior, 20, 335-358.

Ceci, S.J., \& Bruck, M. (1993). Suggestibility of the child witness: A historical review and synthesis. Psychological Bulletin, 113, 403-439.

Clark, D.M., \& Wells, A. (1995). A cognitive model of social phobia. In R.G. Heimberg, M.R. Liebowitz, D.A. Hope, \& F.R. Schneier (Eds.), Social phobia: Diagnosis, assessment and treatment (pp. 69-93). New York: Guilford Press.

Davey, C.L., Hampton, J., Farrell, J., \& Davidson, S. (1992). Some characteristics of worrying: Evidence for worrying and anxiety as separate constructs. Personality and Individual Differences, 13, 133-147.

Davis, S.L., \& Bottoms, B.L. (2002a). Effects of social support on children's eyewitness reports: A test of the underlying mechanism. Law and Human Behavior, 26, 185-215.

Davis, S.L., \& Bottoms, B.L. (2002b). Social support and children's eyewitness testimony. In M.L. Eisen, J.A. Quas, \& G.S. Goodman (Eds.), Memory and suggestibility in the forensic interview (pp. 437-457). Mahwah, NJ: Erlbaum.

Engelberg, E., \& Christianson, S.-A. (2002). Stress, trauma, and memory. In M.L. Eisen, J.A. Quas, \& G.S. Goodman (Eds.), Memory and suggestibility in the forensic interview (pp. 143-163). Mahwah, NJ: Erlbaum.

Eysenck, M.W. (1992). Anxiety: The cognitive perspective. Hove: Erlbaum.

Eysenck, M.W. (1997). Anxiety and cognition: A unified theory. Hove: Psychology Press.

Eysenck, M.W., \& Calvo, M. (1992). Anxiety and performance: The processing efficiency theory. Cognition and Emotion, 6, 409-434.

Farber, I.E., \& Spence, K.W. (1953). Complex learning and conditioning as a function of anxiety. Journal of Experimental Psychology, 120-125.

Fivush, R., Peterson, C., \& Schwarzmueller, A. (2002). Questions and answers: The credibility of the child witnesses in the context of specific questioning techniques. In M.L. 
Eisen, J.A. Quas, \& G.S. Goodman (Eds.), Memory and suggestibility in the forensic interview (pp. 331-354). Mahwah, NJ: Erlbaum.

Garven, S., Wood, J.M., Malpass, R.S., \& Shaw, J.S. (1998). More than suggestion: The effect of interviewing techniques from the McMartin Preschool Case. Journal of Applied Psychology, 83, 347-359.

Gilstrap, L.L., \& Papierno, P.B. (2004). Is the cart pushing the horse? The effects of child characteristics on children's and adults' interview behaviours. Applied Cognitive Psychology, 18, 1059-1078.

Goodman, G., Bottoms, B., Schwartz-Kenney, B., \& Rudy, L. (1991). Children's testimony for a stressful event: Improving children's reports. Journal of Narrative and Life History, 1, 69-99.

Goodman, G.S., Rudy, L., Bottoms, B., \& Aman, C. (1990). Children's concerns and memory: Issues of ecological validity in the study of children's eyewitness testimony. In R. Fivush, \& J. Hudson (Eds.), Knowing and remembering in young children (pp. 249-284). New York: Cambridge University Press.

Gudjonsson, G.H. (1984). A new scale of interrogative suggestibility. Personality and Individual Differences, 5, 303-314.

Gudjonsson, G.H. (1988). Interrogative suggestibility: Its relationship with assertiveness, social-evaluative anxiety, state anxiety and method of coping. British Journal of Clinical Psychology, 27, 159-166.

Gudjonsson, G.H. (1992). The psychology of interrogations, confessions and testimony. Chichester: Wiley and Sons.

Kelly, W.E. (2004). Examining the relationship between worry and trait anxiety. College Student Journal, 38, 370-373.

Krackow, E., \& Lynn, S.J. (2003). Is there touch in the game of Twister? The effects of innocuous touch and suggestive questions on children's eyewitness memory. Law and Human Behavior, 27(6), 589-604.

Moston, S. (1989). Social support and the quality of children's eyewitness testimony. Unpublished Ph.D. thesis, University of Kent.

Moston, S., \& Engelberg, T. (1992). The effects of social support on children's eyewitness testimony. Applied Cognitive Psychology, 6, 61-75.

Nathanson, R., \& Saywitz, K.J. (2003). The effects of the courtroom context on children's memory and anxiety. Journal of Psychiatry and Law, 31, 67-98. 
Quas, J.A., \& Lench, H. C. (2006). Arousal at encoding, arousal at retrieval, interviewer support, and children's memory for a mild stressor. Applied Cognitive Psychology, 19, 1-17. Rachman, S. (2004). Anxiety (2nd ed.). Hove: Psychology Press.

Ridley, A.M., \& Clifford, B.R. (2004). The effects of anxious mood induction on suggestibility to misleading post-event information. Applied Cognitive Psychology, 18, 233244.

Ridley, A.M., Clifford, B.R., \& Keogh, E. (2002). The effects of state anxiety on the suggestibility and accuracy of child eyewitnesses. Applied Cognitive Psychology, 16, 547558.

Roberts, K.P., Lamb, M.E., \& Sternberg, K.J. (2004). The effects of rapport-building style on children's reports of a staged event. Applied Cognitive Psychology, 18, 189-202.

Sarason, I.G. (1980). Introduction to the study of test anxiety. In I.G. Sarason (Ed.), Test anxiety: Theory, research and applications (pp. 3-14). Hillsdale, NJ: Erlbaum.

Saywitz, K.J., Goodman, G.S., Nicholas, E., \& Moan, S.F. (1991). Children's memories of a physical examination involving genital touch: Implications for reports of child sexual abuse. Journal of Consulting and Clinical Psychology, 57, 682-691.

Schooler, J., \& Loftus, E.F. (1986). Individual differences and experimentation: Complementary approaches to interrogative suggestibility. Social Behaviour, 1, 105-112.

Spielberger, C.D. (1972). Anxiety as an emotional state. In C.D. Spielberger (Ed.), Anxiety: Current trend in theory and research (Vol. 1). New York: Academic Press.

Spielberger, C.D., Edwards, C.D., Lushene, R., Montuori, J., \& Platzek, D. (1973). STAI-C preliminary manual for the state-trait anxiety inventory for children. Palo Alto, CA: Consulting Psychologists Press.

Spielberger, C.D., Gorsuch, R.L., \& Lushene, R.E. (1970). Manual for the state-trait anxiety inventory. Palo Alto, CA: Consulting Psychologists Press.

Thierry, K.L., \& Spence, M.J. (2004). A real-life event enhances the accuracy of preschoolers' recall. Applied Cognitive Psychology, 18, 297-309.

Tousignant, J.P., Hall, D., \& Loftus, E.F. (1986). Discrepancy detection and vulnerability to misleading postevent information. Memory and Cognition, 14, 329-338.

Wells, A. (2005). Worry, intrusive thoughts, and generalized anxiety disorder: The metacognitive theory and treatment. In D.A. Clark (Ed.), Intrusive thoughts in clinical disorders: Theory, research and treatment (pp. 119-144). New York: Guilford Press.

Williams, J.M.G., Watts, F.N., MacLeod, C., \& Mathews, A. (1988). Cognitive psychology and emotional disorders. Chichester: Wiley and Sons. 
Wolfradt, U., \& Meyer, T. (1998). Interrogative suggestibility, anxiety and dissociation among anxious patients and normal controls. Personality and Individual Differences, 25, $425-432$.

Wood, J.M., McClure, K.A., \& Birch, R.A. (1996). Suggestions for improving interviews in child protection agencies. Child Maltreatment, 1, 223-230.

Zaragoza, M.S., \& Lane, S.M. (1994). Source misattributions and the suggestibility of eyewitness memory. Journal of Experimental Psychology: Learning, Memory and Cognition, $20,934-945$.

\section{APPENDIX}

\section{Summary of the movie clip}

The clip showed girls sneaking out of their bedroom at night to find something to eat in the kitchen while the headmistress and the cook are playing cards in the living room. While gathering ingredients to make a cake, the neighbour's boy comes screaming at the kitchen window which scares the girls. Some of the girls drop the eggs, flour and water they were holding, making a mess. Having heard the noise, the headmistress and the cook come running into the kitchen to find the mess and telling the girls to clean everything. 